This item was submitted to Loughborough's Research Repository by the author.

Items in Figshare are protected by copyright, with all rights reserved, unless otherwise indicated.

\title{
The mechanism of the air-jet texturing: the role of wetting, spin finish and friction in forming and fixing loops
}

PLEASE CITE THE PUBLISHED VERSION

http://dx.doi.org/10.1177/0040517506062614

PUBLISHER

(c) Sage

VERSION

AM (Accepted Manuscript)

\section{PUBLISHER STATEMENT}

This work is made available according to the conditions of the Creative Commons Attribution-NonCommercialNoDerivatives 4.0 International (CC BY-NC-ND 4.0) licence. Full details of this licence are available at: https://creativecommons.org/licenses/by-nc-nd/4.0/

\section{LICENCE}

CC BY-NC-ND 4.0

\section{REPOSITORY RECORD}

Acar, Memis, Sule Bilgin, Hendrik K. Versteeg, N. Dani, and W. Oxenham. 2019. "The Mechanism of the Airjet Texturing: The Role of Wetting, Spin Finish and Friction in Forming and Fixing Loops". figshare. https://hdl.handle.net/2134/19350. 


\title{
THE MECHANISM OF THE AIR-JET TEXTURING: THE ROLE OF WETTING, SPIN FINISH AND FRICTION IN FORMING AND FIXING LOOPS
}

\author{
M Acar ${ }^{*}$, S Bilgin ${ }^{\ddagger}$, H K Versteeg ${ }^{*}$, N Dani $^{\dagger}$ and W Oxenham ${ }^{\dagger}$ \\ *Mechanical and Manufacturing Engineering, Loughborough University, UK \\ ${ }^{+}$College of Textiles, North Carolina State University, Raleigh, NC, USA \\ ${ }^{\ddagger}$ Formerly of Loughborough University, UK \\ Mechanical and Manufacturing Engineering \\ Loughborough University \\ Leicestershire, LE11 3LB, United Kingdom \\ m.acar@lboro.ac.uk
}

\begin{abstract}
A comprehensive review of the roles played by the airflow, wetting and spin finish on the air-jet texturing process is given. An experimental investigation of the air-jet texturing process using residual spin finish, yarn-to-yarn static and kinetic friction, filament strength, filament diameter, and on-line tension measurements and high-speed cinephotography is reported. Filament yarn motion in different regions of the texturing nozzle during dry and wet texturing is analysed. It is found that water acts as lubricant to reduce friction between the filaments in the wet texturing process as the filament yarn travels through the nozzle enabling easier relative motion of the filaments resulting in enhanced entanglement. Wet texturing also reduces spin finish on the yarn surface, which in turn, causes an increase in static friction between the filaments of the textured yarn resulting in better fixing of the loops and consequently superior yarns.
\end{abstract}

\section{Introduction}

The air-jet texturing process produces spun-like yarns by modifying the uniform arrangement of the synthetic continuous multi-filament yarns and entangling them using a supersonic air stream delivered by a texturing nozzle designed for this purpose. Modern industrial practice often involves wetting of the filament yarns during the process by passing the supply yarn through a water bath, wetting head or spray unit, resulting in improved process stability and hence in better quality yarns. Wet textured yarn have higher number of smaller, more stable, loops which are more securely anchored into the yarn core which itself is more compact and uniform.

Yarns passing through the water applicator carry along the applied water until they reach the texturing nozzle where the secondary flow causes a substantial amount of this water to be sprayed away, letting only a very small amount of water to be entrained into the nozzle. When this entrained water, usually adhered to the surface of the filaments and trapped between them, meets the incoming jets from the inlet orifices at supercritical speeds, it is then blown off the filaments 
and broken down into very small mist droplets which are blown out of the nozzle with the supersonic primary flow emerging from the nozzle.

Since early sixties considerable research have been conducted to reveal the mechanism of air-jet texturing. Wray and Acar [24] gives an overview of the research up to 1990. Many hypotheses have been put forward regarding the mechanism of loop formation in air-jet texturing process but there appears to be no consensus among the researchers.

\section{Literature Survey}

\section{The Role of Airflow}

Bock [11], and Bock and Luenenschloss [12] investigated the airflow experimentally. Bock and Luenenschloss [13] then used a two-dimensional rectangular cross-sectioned convergingdiverging nozzle that simulated the Taslan nozzle with two parallel glass sides. This enabled them to visualise the filaments and shockwaves inside and just outside the nozzle using stills photography and instantaneous Schlieren photography. They suggested that multi-filament yarn is opened in the nozzle by turbulence and/or gradients of the flow velocity; the filaments blown out pass through a zone of high air turbulence, and are decelerated by the subsequent drop of the dynamic pressure.

Bock and Luenenschloss conjecture that the effect on texturing arises from the susceptibility of slack yarns inside the nozzle to the large flow forces associated with condensation shocks. They suggested that shockwaves in the region just outside the nozzle give rise to large retarding forces on the filaments therefore assist 'interlacing' of the filaments causing them to turn through a 90 degree angle and experience relative motion.

Acar et al [4-6] a so investigated the airflow and fluid forces acting on the filaments using Heberlein HemaJet type texturing nozzle experimentally and visualised shockwaves outside the nozzle using a shadowgraph technique. They disagreed with the above hypotheses by suggesting that although shock waves exist in free, undisturbed flows they are at least partially destroyed by the presence of filament yarn in the nozzle during the texturing process. Furthermore shock strength varies according to the particular nozzle type. As nozzles providing varying degrees of shock strength are all effective in producing commercially viable textured yarns, they concluded that the effect of pressure waves on the filament's motion is negligible and that any texturing mechanism based on the presence of such waves is probably invalid.

They analysed the positions of filament using instantaneous single frame still photographs and high-speed cine-photography observing the region just outside the air-jet texturing nozzles [7]. The latter provided a continuous record of the yarn motion and showed the filaments emerging from the nozzle and being drawn at right angles (by the take-up rollers). Demir [15] too investigated texturing with high-speed cine photography. The cine-film studies were carried out in conjunction with detailed mapping of the velocity distribution around the nozzle exit.

Acar et al [4] experimentally observed that the flow from the texturing jet at the usual air pressures used in texturing is supersonic, turbulent, slightly asymmetric and non-uniform in profile. Acar et al [8] also studied the airflow in texturing nozzles theoretically and developed a mathematical model of the flow through cylindrical nozzles, which was verified by experimental results. Their description of the mechanism of texturing emphasises the role of spatial velocity variations and turbulence in the air stream, which cause the individual filaments to travel at differential speeds owing to the variable fluid forces acting on them. The free excess lengths 
provided by the overfed filaments enable the faster moving filaments to slip and be displaced longitudinally with respect to the slower moving filaments. The degree of these longitudinal displacements is affected by the local drag and frictional forces instantaneously acting on the filaments and limited by the degree of overfeed. The emerging filaments, when their direction is turned by $90^{\circ}$ angle by the take-up rollers, are therefore forcibly bent into bows and arcs by the fluid forces acting on them. These are then simultaneously entangled and formed into fixed stable loops within the textured yarn.

Sengupta et al [23] reviewed the texturing mechanism put forward by a number of researchers up to 1990 and concluded that there appears to be no consensus among the researchers regarding any particular hypothesis and more detailed investigation would be necessary to understand the mechanism of the air jet texturing process. Based on the reviewed research Sengupta et al made a rather unconvincing attempt to explain the mechanism of air jet texturing.

\section{The Role of Water}

One of the early hypotheses suggested that the presence of water alters the fluid flow behavior by condensation shock waves, Fischer [17]. Bock and Luenenschloss [12] claimed that pre-wetting of yarn leads to strengthen the shock waves and thereby improves the interlacing of the filaments. When the filaments interlace, loops projecting from the yarn are formed by the differently sized filament bends.

Artunc [9] showed that the quantity of water is only critical at consumption rates of less than 0.2 litre/hour. Similarly Bock and Luenenschloss [12] found that when the water application was reduced to 0.1 litre/hour did it cause significant decreases in process stability, number of loops produced, and tensile strength of the textured yarn. Acar and Demir [3] showed that the critical amount of water is even smaller than 0.1 litre/hr, and as low as 0.06 litre/hr. There appears to be a consensus that only a small amount of water is needed to have the desired effect on the texturing process, and hence on the resultant yarn properties.

Acar et al [7] assumed that the interaction between a moist yarn and the air stream creates a fine mist of small water droplets mixing into the air flow. They used homogeneous two-phase flow theory to calculate the momentum that is extracted from the airflow to maintain the speed of the water droplets. Using generous estimates of the water mixing into the air-jet they found that the presence of water caused a small reduction (of order 1\%) of the mean air velocity. This was deemed too small to affect the texturing process.

They attributed the improvement in texturing process with yarn wetting to the lubrication effect reduction in interflament friction and friction between the filaments and other surfaces during the process. Reduction in interflament friction and friction between filament and contacting surfaces leads to a significant increase in the resultant force acting on the filaments. This in turn causes easier longitudinal displacement of the filaments with respect to each other, enhancing the formation of loops, which then become entangled as they emerge from the nozzle.

To prove this hypothesis Acar et al [7] designed a series of experiments. The tension in the filament yarn prior to its entrance into the nozzle is normally the result of the fluid forces acting on the yarn minus the friction forces that oppose the yarn motion. They clearly demonstrated beyond doubt that the dynamic friction was significantly reduced when the yarn was wet textured due to the lubricating effect of water. 
Acar and Demir [3] showed that there was no identifiable difference in the shockwave patterns using shadowgraphs of wet and dry air streams outside an industrial texturing nozzle and concluded that the airflow was unaffected by the presence of water. They, therefore, concluded that the texturing mechanism based on existence of stronger shock waves in wet texturing is not credible.

Kothari et al $[18,19]$ questioned the role of wetting as a lubricant, emphasising that, if the reduction in friction alone is responsible for better texturing, any two parent yarns that have the same friction levels, regardless of whether one is dry textured and the other wet textured, would result in similar structures. Their results confirmed that the presence of water consistently gives improved texturing even if the inter-filament friction levels are similar under dry and wet conditions. However they did not propose an alternate explanation as regards to the effects of water, but instead reverted to the hypothesis of Bock and Luenenschloss [11], reiterating the role of condensation shock waves without providing any evidence. The procedures used by Kothari et al in the pre treatment of Nylon yarn, e.g. soaking the yarn in water for a long period before conducting the tests, since these did not reflect the practices used in air-jet texturing, hence the claims they make to the effect of water on texturing nylon yarns are very questionable.

Chand [14] presented a critical review of the role of water in air-jet texturing based on the work of various authors, already mentioned here. He speculated that the main factor causing improvements in texturing with wetting is probably not the reduction in friction but the change in fluid behaviour inside the jet, based on the assumption that condensation shocks play a role in texturing, a claim which had not been substantiated by any of the publications that he reviewed, but discredited by Acar and Demir [3].

\section{The Role of Spin Finish}

It has been experimentally proven that while dry texturing removes only a negligible amount of spin finish from the surface of the yarn, wet texturing removes a significant amount, Acar [2]. The level of spin finish removal in wet texturing is always a significant proportion of its original level, varying for different yarns.

\section{Experimental Procedure}

In this paper we re-examine the role of wetting, spin finish and friction on the air-jet texturing process. We report a high-speed cine-photography study, which has not been reported before, to characterise filament yarn motion inside the nozzle during dry and wet texturing. To this effect we have simultaneously filmed the yarn motion inside and just outside a texturing nozzle with a rectangular cross-section. Glass sidewall of the experimental nozzle enabled high-speed cinephotography of the filaments inside the nozzle.

We have also investigated the removal of spin finish during texturing. We also report static and kinetic frictional properties of the filament yarn samples to examine whether wetting does cause a change in the yarn-to-yarn friction properties of the filament yarn. We assess the implications of these changes in the inter-filament friction for the final entanglement and loop fixing stages of the yarn formation and re-evaluate the mechanism of air-jet texturing.

\section{Supply Yarns}

A set of 5 different Polyester and Nylon supply yarns of different linear densities (Table I) was textured using the same texturing conditions. We have measured the kinetic friction, spin finish content, filament strength and diameter, and the on line yarn tension. 
Table I: Supply filament yarns used in experiments

\begin{tabular}{|l|l|c|c|c|c|c|c|}
\hline & Yarn Type & $\begin{array}{c}\text { Linear } \\
\text { Density } \\
(\text { dtex })\end{array}$ & $\begin{array}{c}\text { Number } \\
\text { of } \\
\text { filaments }\end{array}$ & $\begin{array}{c}\text { Cross } \\
\text { Sectional } \\
\text { Shape }\end{array}$ & $\begin{array}{c}\text { Moisture } \\
\text { regain } \\
(\%)\end{array}$ & $\begin{array}{c}\text { Tenacity } \\
\text { (gf/dtex) }\end{array}$ & $\begin{array}{c}\text { Shear } \\
\text { modulus } \\
(\mathrm{GPa})\end{array}$ \\
\hline 1 & 140/50 Dacron & 140 & 50 & Trilobal & 0.4 & 6 & 0.8 \\
\hline 2 & 150/34 Dacron & 150 & 34 & Circular & 0.4 & 6 & 0.8 \\
\hline 3 & 240/54 Dacron & 240 & 54 & Circular & 0.4 & 6 & 0.8 \\
\hline 4 & 156/102 Nylon & 156 & 102 & Trilobal & 4.1 & 5.5 & 0.4 \\
\hline 5 & 100/34 Nylon & 100 & 34 & Circular & 4.1 & 5.5 & 0.4 \\
\hline
\end{tabular}

\section{Nozzle Design}

The nozzle used in our research had a $25.4 \mathrm{~mm}$ (1 inch) long main channel, $1.5 \mathrm{~mm}$ wide, 1.0 $\mathrm{mm}$ deep and the primary flow exit length was $10 \mathrm{~mm}$ long with a bell-shaped diverging exit section, simulating the HemaJet nozzle. Figure 1 shows the general design concept of the experimental nozzle. Details of the design are given in Bilgin et al [10] where it was shown that such rectangular nozzles perform as well as the industrial texturing nozzles in producing textured yarns.

\section{Spin-Finish Content Measurement}

Spin finish content of the supply yarn, wet textured and dry textured yarn were measured using the following procedure: Ten-gram samples were heated to $125^{\circ} \mathrm{C}$ for $2.5 \mathrm{hrs}$ and subsequently placed in a desicator for a further 30 mins to remove moisture. Precision scales (accuracy: 0.001 g) were used to obtain the bone-dry weight "before extraction". The samples were then placed in a Soxhlett extraction apparatus (AATCC, 1997) for 6 hrs, where the extraction of spin finish was achieved using hexane gas and water. Next, the samples were heated again and desicated (see above) and the "after extraction" weight determined.

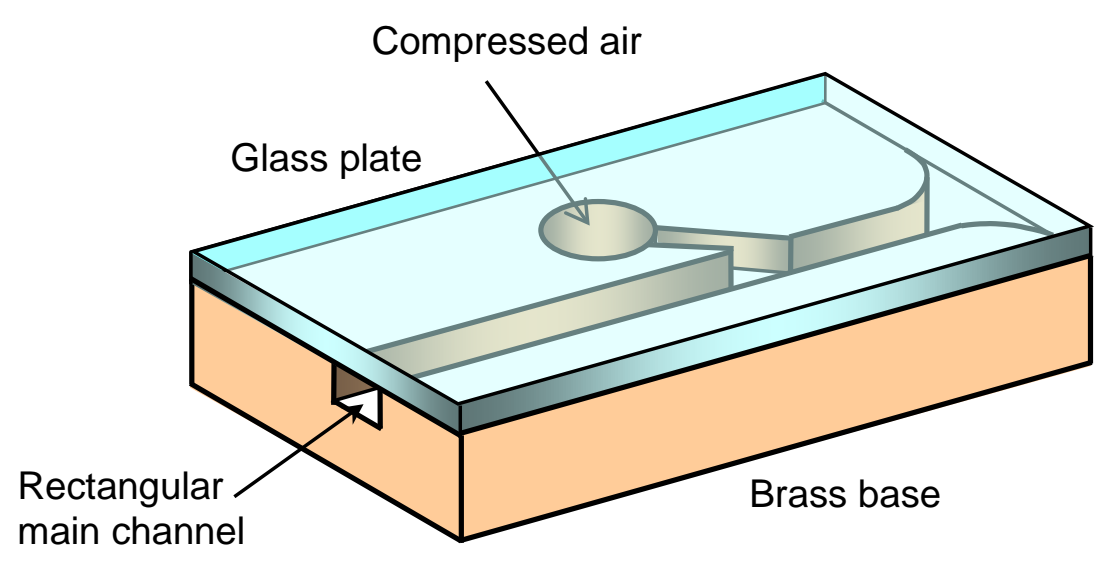

Figure 1: Design concept for the experimental nozzle with rectangular channels 
Furthermore, in order to correlate the frictional behaviour with the amount of spin finish removed, it became necessary to measure the spin finish percentage in the straight yarns passed through the texturing machine without texturing (at 0 overfeed) using both wet and dry texturing conditions, which simulated the spin finish removal in wet and dry texturing conditions respectively.

\section{Static Friction Measurement}

An indication of inter-filament friction can be obtained by measuring yarn-to-yarn friction, Kothari et al $[18,19]$. We have devised a technique based on the methods suggested by Lindberg and Gralen [20] and Prevorsek and Sharma [22] to measure the yarn-to-yarn static friction under dry and wet conditions. The technique, illustrated in Figure 2, basically involves measuring the tension in the yarn due to friction when a slip occurs between the two yarns. Two yarns are twisted around each other $n$ times. A constant tension, $\mathrm{T}_{1}$, is applied to one of the yarns.

One end of the second yarn is left free and an incrementally increasing amount of tension is applied to the other end of the yarn until slippage occurs. It is clear that the higher the slippage tension $\mathrm{T}_{2}$ the higher the yarn-to-yarn friction. In all friction experiments $\mathrm{n}$ was taken as 50 and $\mathrm{T}_{1}$ was chosen as $50 \mathrm{~g}$, both of which were determined experimentally for optimum conditions.

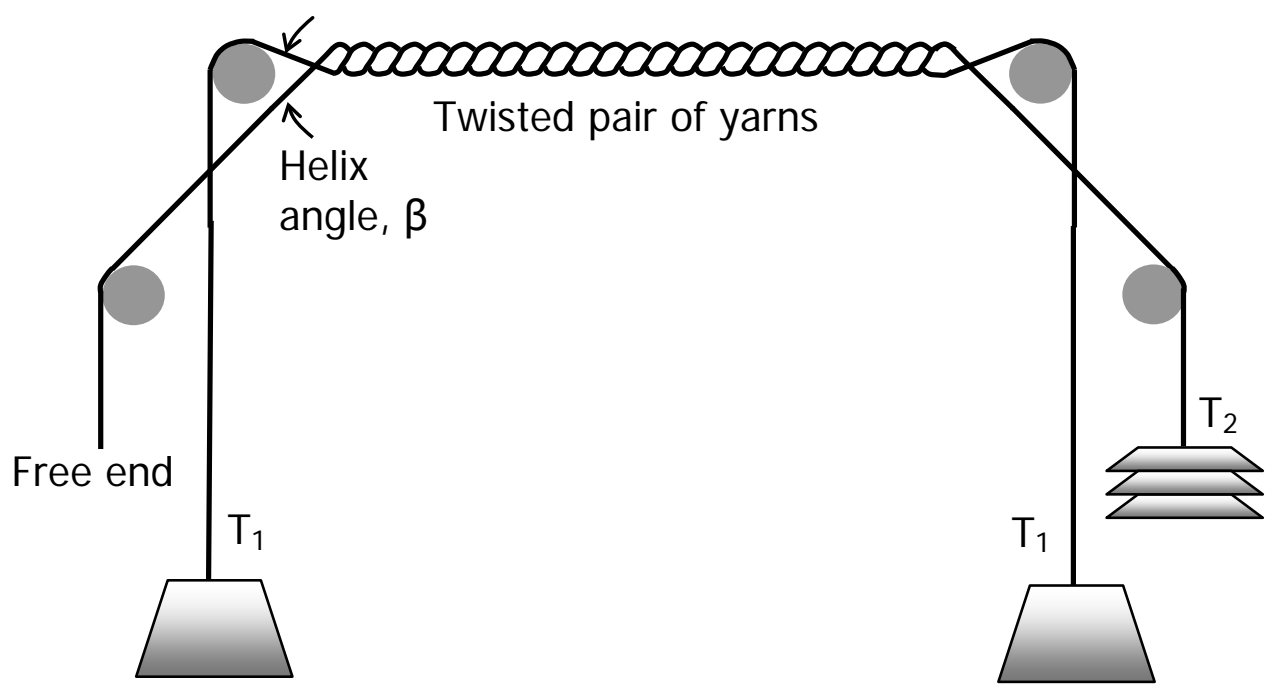

Figure 2: The concept of yarn-to-yarn static friction measurements

\section{Kinetic Friction Measurement}

First the supply yarn was run through the texturing nozzle under dry and wet conditions separately simulating dry and wet texturing processes, but with zero overfeed to prevent any loop formation. Hence the processed yarns maintained the loop free structure of the feed yarn but their spin finish contents have been reduced by the wet and dry texturing processes to their respective levels obtained from such processes. Then Lawson-Hemphill Constant Tension Transport Instrument [21] with Friction Tests Attachment was used to measure yarn-to-yarn dynamic friction. The machine speed for the yarn-to-yarn test was set at the recommended 20 
$\mathrm{m} / \mathrm{min}$ yarn speed. The input tension $\left(T_{1}\right)$ was set according to the recommended convention of 1g/tex. The output tension $\left(T_{2}\right)$ was obtained directly from the integrated tensiometer. The coefficient of friction was calculated using the equation as below:

$$
\mu_{1}=\ln \left(\frac{T_{2}}{T_{1}}\right) \div\{4 \pi(n-0.5) \times \operatorname{Sin}(\beta / 2)\}
$$

we used $\mathrm{n}=3$ wraps as recommended and the angle of wrap $\beta=35^{\circ} \pm 1$.

\section{Individual filament strength tests}

We have tested the strength of the constituent filaments of the supply yarns and wet and dry textured yarns. Following the recommendations of ASTM D3882 we tested 25 filament samples of each type of yarn using the fibre tensile/slack compensation method to an accuracy of $0.1 \mathrm{cN}$. The specimen length used for individual filament strength tests was $25.4 \mathrm{~mm}$ (1 inch).

\section{Filament diameter measurements}

An optical microscope was used to measure the filament diameters of the supply yarns, and wet and dry textured yarns. The yarn was cut to a very short length, a drop of mineral oil was then put on the yarn and the filaments were separated using a needle. The refractive index of the medium (mineral oil) being different from that of the filament, one could see the filaments clearly. The filaments were then viewed and their diameter was measured to an accuracy of 1 micron.

\section{On-line tension measurements}

The tension measurements were taken using a hand held mechanical precision tension meter at the feed and the mechanical stretch (stabilising) regions of the texturing process to an accuracy of $1 \mathrm{cN}$.

\section{High Speed Cine-Photography}

We take advantage of our rectangular nozzle design, which allows viewing of the filament/flow interaction through a flat glass side-wall which does not suffer from image distortion associated with circular cross-sectioned industrial nozzles. We used a high-speed cine-photography system based on a Photec rotating prism $16 \mathrm{~mm}$ high-speed cine-camera in conjunction with an Oxford Lasers CU-10 copper vapour pulse laser illumination source with fibre optic delivery to record films with around 2000 consecutive images of the yarn motion at a frame rate of $6000 \mathrm{fps}$. The 25 ns pulse width of the copper vapour laser per image frame was sufficient to freeze the fastest filament motions.

We have recorded on high-speed cine-films simultaneously the filament yarn running through the texturing nozzle and emerging from it during the texturing process. Texturing conditions were kept constant throughout the experiment at $800 \mathrm{kPa}$ (gauge) air pressure, $200 \mathrm{~m} / \mathrm{min}$ yarn speed, $20 \%$ overfeed, $4 \%$ stabilising draw rate, and a water flow rate of 1 litre/hr in the wet texturing. For the high-speed cine-photography results presented here we have used PET 176/66 feed yarn. We believe that this yarn is representative, since observations of the texturing process with different yarns of similar linear density at this laboratory has shown that the general features of the yarn motion are insensitive to the yarn type. 


\section{Results}

\section{Spin Finish}

In Table II we compare the spin finish content of the supply yarn, and dry and wet textured yarns. The results show that the wet textured yarns have a lower spin finish percentage on their surface after texturing. As expected, wet texturing removes significantly more spin finish then dry texturing, which agrees with our previous findings (Acar, 1988).

Table II. Spin finish on the supply yarn and the yarns simulating wet and dry texturing conditions as percentage of the yarn weight

\begin{tabular}{|l|l|l|l|l|l|}
\hline & \multicolumn{1}{|c|}{$\begin{array}{c}\text { Supply } \\
\text { Yarn }\end{array}$} & $\begin{array}{c}\text { Dry } \\
\text { Textured }\end{array}$ & $\begin{array}{c}\text { Dry } \\
\text { Simulated }\end{array}$ & $\begin{array}{c}\text { Wet } \\
\text { Textured }\end{array}$ & \multicolumn{1}{|c|}{$\begin{array}{c}\text { Wet } \\
\text { Simulated }\end{array}$} \\
\hline 150/50 Dacron & 0.610 & 0.553 & 0.562 & 0.075 & 0.031 \\
\hline 150/34 Dacron & 0.708 & 0.605 & 0.586 & 0.182 & 0.026 \\
\hline 240/54 Dacron & 0.460 & 0.405 & 0.311 & 0.076 & 0.184 \\
\hline 156/102 Nylon & 0.522 & 0.432 & 0.497 & 0.316 & 0.302 \\
\hline 100/34 Nylon & 0.750 & 0.461 & 0.465 & 0.338 & 0.391 \\
\hline
\end{tabular}

\section{Yarn-to-yarn Static Friction}

The inter-filament friction and yarn-to-yarn friction characteristics of filament yarns are dependent on the quantity of spin finish on the yarn and on the presence of water. Yarn-to-yarn static friction tests were conducted for three different scenarios as shown in Table III. Dry supply yarn with its original spin finish (Specimen I) has higher static friction than the same yarn tested under wet conditions (Specimen II), confirming earlier claims of Acar et al (1988) that wetting acts as a lubricant and reduces inter-filament friction for polyester supply yarns. Our experiments also show that yarn with reduced spin finish (Specimen III), representing the yarn after wet texturing, has even higher static friction than the original supply yarn (Specimen I). This finding forms a key part of our re-appraisal of the air jet texturing mechanism.

Table III: Yarn-to-yarn friction experiments

\begin{tabular}{|l|c|}
\hline Friction Tests & Tension (cN) \\
\hline $\begin{array}{l}\text { Yarn specimen I: dry tested supply yarn with original (high) spin } \\
\text { finish level (0.7\%) representing inter-filament friction } \\
\text { characteristics throughout dry texturing }\end{array}$ & 34.3 \\
\hline $\begin{array}{l}\text { Yarn specimen II: wet tested supply yarn with original (high) spin } \\
\text { finish level (0.7\%) simulating inter-filament friction in the feed } \\
\text { zone and inside the texturing nozzle }\end{array}$ & 29.4 \\
\hline $\begin{array}{l}\text { Yarn specimen III: dry tested supply yarn with reduced spin finish } \\
\text { level (0.2\%) simulating inter-filament friction in the textured yarn } \\
\text { just after wet texturing }\end{array}$ & 38.8 \\
\hline
\end{tabular}




\section{Yarn-to-yarn Kinetic Friction}

The objective of the kinetic friction tests was to evaluate the yarn-to-yarn coefficients of friction of the selected supply yarns.

We have tested yarns under dry conditions only since moisturising the yarn during testing would have been harmful to the CTT instrument used in tests. We have observed that the yarn-to-yarn coefficient of kinetic friction is not sensitive to spin-finish content in dry testing conditions. The differences between the supply yarn and yarns simulating dry and wet texturing conditions are found to be insignificant, as shown in Table IV. However the lubricating effect of wetting the filament yarn to reduce friction has been very clearly demonstrated by Acar et al [7] in an earlier study and similar reduction in kinetic friction should also be observed when wet tested.

Table IV: Coefficient of yarn to yarn kinetic friction

\begin{tabular}{|l|l|c|c|c|}
\hline & Yarn Type & Supply Yarn & $\begin{array}{c}\text { Simulating Dry } \\
\text { Textured Yarn }\end{array}$ & $\begin{array}{c}\text { Simulating Wet } \\
\text { Textured Yarn }\end{array}$ \\
\hline 1 & $140 / 50$ Dacron & 0.154 & 0.159 & 0.165 \\
\hline 2 & $150 / 34$ Dacron & 0.129 & 0.128 & 0.133 \\
\hline 3 & $240 / 54$ Dacron & 0.130 & 0.132 & 0.133 \\
\hline 4 & $156 / 102$ Nylon & 0.164 & 0.170 & 0.167 \\
\hline 5 & $100 / 34$ Nylon & 0.148 & 0.151 & 0.148 \\
\hline
\end{tabular}

\section{Stabilizing Zone Tension}

Table V shows the measured values of the stabilising tension during wet and dry texturing. Acar et al [5] have previously shown that a higher stabilising tension in the mechanical stretch region is associated with improved quality of the textured yarn. Stabilising zone tension was measured and used as an indication of the quality of the textured yarn produced.

Table V Stabilising zone tension (cN)

\begin{tabular}{|c|l|c|c|}
\hline & Yarn Type & Dry Texturing & Wet Texturing \\
\hline 1 & $140 / 50$ Dacron & 22 & 38.5 \\
\hline 2 & $150 / 34$ Dacron & 10 & 27 \\
\hline 3 & $240 / 54$ Dacron & 11 & 35 \\
\hline 4 & $156 / 102$ Nylon & 11.5 & 35 \\
\hline 5 & $100 / 34$ Nylon & 6.5 & 11.2 \\
\hline
\end{tabular}

\section{Filament Diameter and Tensile Strength}

We have compared the diameter and strength of individual filaments of the supply yarn with those of wet and dry textured yarns of each yarn type. Data were taken for all yarns given in Table I. No significant differences were found across all data. Table VI shows that the filament 
diameter measurements indicate very slight increase for polyester yarns whereas nylon yarns shows very slight decrease. These differences are within the measurement errors.

Table VI: Filament diameter $(\mu \mathrm{m})$

\begin{tabular}{|c|l|c|c|c|c|}
\hline & Yarn Type & $\begin{array}{c}\text { Supply } \\
\text { Yarn }\end{array}$ & $\begin{array}{c}\text { Dry Textured } \\
\text { Yarn }\end{array}$ & $\begin{array}{c}\text { Wet Textured } \\
\text { Yarn }\end{array}$ & $\begin{array}{c}\text { Maximum } \\
\text { \% Change }\end{array}$ \\
\hline 1 & $140 / 50$ Dacron & 19.75 & 20.33 & 20.38 & 3.2 \\
\hline 2 & $150 / 34$ Dacron & 21.63 & 21.50 & 22.13 & 2.3 \\
\hline 3 & $240 / 54$ Dacron & 21.25 & 21.50 & 21.75 & 2.4 \\
\hline 4 & $156 / 102$ Nylon & 17.25 & 16.33 & 16.88 & -5.3 \\
\hline 5 & $100 / 34$ Nylon & 17.88 & 17.63 & 17.75 & -1.4 \\
\hline
\end{tabular}

Table VII shows that the filament strength measurements show slight but consistent decrease across all yarns tested. The decrease in filament strength in wet texturing is slightly higher than that of dry texturing which could be due to the higher forces Acar et al [6] and stabilizing tension observed in wet texturing Table V. Filaments with higher linear density show smaller reduction in strength.

These findings, however, indicate that there is very slight change in filament diameter and strength due to the texturing process.

Table VII: Filament strength (cN)

\begin{tabular}{|l|l|c|c|c|c|}
\hline & Yarn Type & $\begin{array}{c}\text { Supply } \\
\text { Yarn }\end{array}$ & $\begin{array}{c}\text { Dry Textured } \\
\text { Yarn }\end{array}$ & $\begin{array}{c}\text { Wet Textured } \\
\text { Yarn }\end{array}$ & $\begin{array}{c}\text { Maximum } \\
\text { \% Change }\end{array}$ \\
\hline 1 & 140/50 Dacron (2.8) & 8.4 & 7.7 & 6.7 & -20.3 \\
\hline 2 & 150/34 Dacron (4.4) & 16.8 & 16.6 & 15.8 & -6.0 \\
\hline 3 & 240/54 Dacron (4.4) & 17.9 & 17.3 & 17.2 & -3.9 \\
\hline 4 & 156/102 Nylon (1.5) & 8.3 & 7.4 & 7.3 & -12.0 \\
\hline 5 & $100 / 34$ Nylon (2.9) & 13.5 & 12.6 & 12.2 & -9.6 \\
\hline
\end{tabular}

\section{High Speed Cine-Photography}

Figure 3 shows prints of a randomly selected set of 10 consecutive images of the filaments from such a film. We have performed detailed measurements on a sample of 100 consecutive frames of each film representing wet and dry texturing processes. With a texturing speed of $200 \mathrm{~m} / \mathrm{min}$ and an instantaneous frame rate around 6000 frames per second; this corresponds to the passage of approximately $30 \mathrm{~mm}$ of yarn. This is more than adequate to capture a substantial number of texturing events. We have characterised the nature of the yarn motion through measurement of three key locations in each image: 
$\mathrm{L}_{1}$ : the starting points of the separation of filaments inside the nozzle

$\mathrm{L}_{2}$ : the starting points of the loop formation process.

$\mathrm{L}_{3}$ : the furthest point of the loops reached outside the nozzle

These regions are illustrated in Figure 4. Table VIII gives the average values and standard deviations of the distances $\mathrm{L}_{1}, \mathrm{~L}_{2}$ and $\mathrm{L}_{3}$.

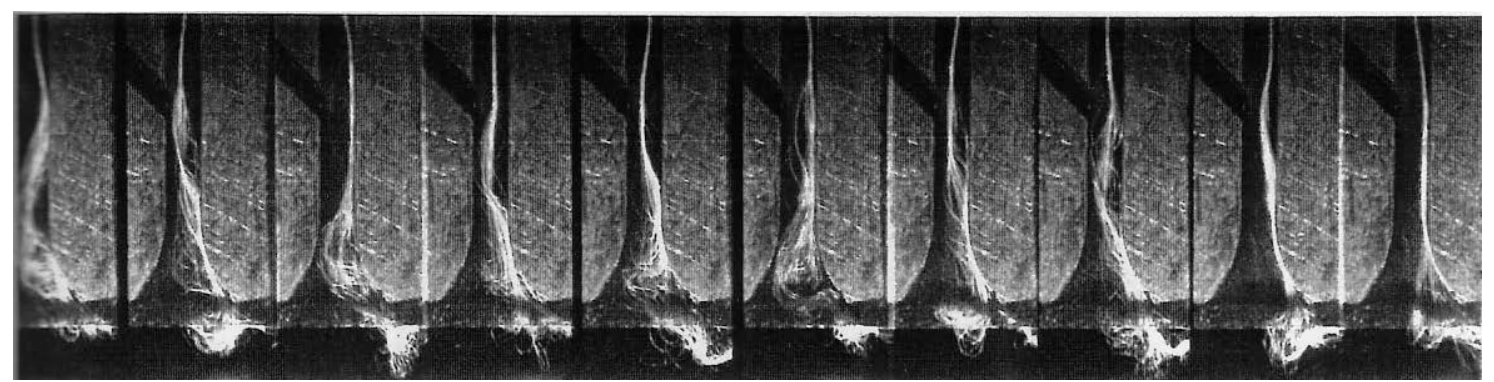

Figure 3: Consecutive images from the high-speed photographs of the filaments inside the texturing nozzle.

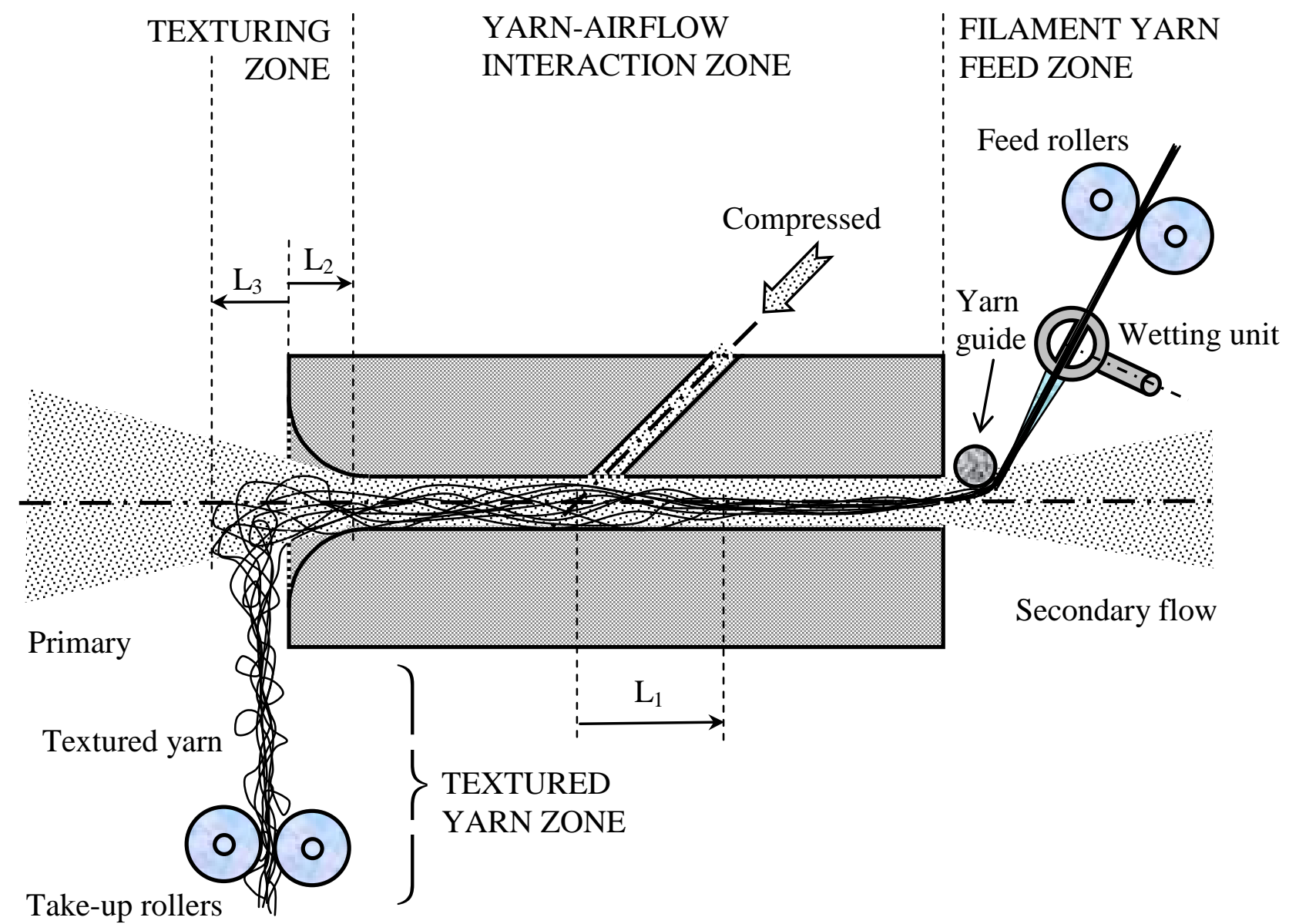

Figure 4: Schematic illustration of the air jet texturing nozzle, air flow and filaments 
Table VIII: Summary of the data from the high-speed films

\begin{tabular}{|l|c|c|c|c|}
\hline & \multicolumn{2}{|c|}{ Wet Texturing } & \multicolumn{2}{c|}{ Dry Texturing } \\
\hline & Mean & s.d. & Mean & s.d. \\
\hline $\mathrm{L}_{1}(\mathrm{~mm})$ & $\mathbf{1 . 5 1}$ & 0.69 & $\mathbf{1 . 3 3}$ & 0.96 \\
\hline $\mathrm{L}_{2}(\mathrm{~mm})$ & $\mathbf{0 . 7 2}$ & 0.67 & $\mathbf{0 . 2 5}$ & 0.61 \\
\hline $\mathrm{L}_{3}(\mathrm{~mm})$ & $\mathbf{1 . 4 1}$ & 0.56 & $\mathbf{2 . 1 0}$ & 0.60 \\
\hline
\end{tabular}

It should be noted that the measurements of parameters $L_{1}, L_{2}$ and $L_{3}$ involve a certain amount of subjective judgement. Where it was impossible to estimate reasonable locations we have omitted the values. In spite of these difficulties the values and standard deviations of these measured distances provide useful information regarding key events associated with the yarn and filament dynamics of air jet texturing.

\section{Discussion}

\section{Yarn Motion during Dry and Wet Texturing}

When we contrast the yarn motion during the two processes we observe that, in wet texturing, the yarn remains close to the nozzle exit contour and in dry texturing the process experiences higher levels of unsteadiness. Visual observation of the texturing process by alternately switching from dry to wet processing conditions also supports this view. Moreover, we also observed that during dry texturing the filaments are intermittently pulsed considerable distance away from the nozzle probably causing larger size loops to be formed.

High-speed films show that the pre-conditions for loop formation are created inside the nozzle by the opening up of the filament bundle. Superficially, the yarn and filament motion during dry and wet texturing appears to be largely similar. The quantitative analysis highlights some important differences, which fits in with our other measurements suggesting improved mobility of the filaments during wet texturing. Firstly, the larger average value of the separation point distance, $\mathrm{L}_{1}$ shows that the separation of filaments inside the nozzle starts earlier in the case of wet texturing. The higher standard deviation of $\mathrm{L}_{1}$ under dry texturing conditions indicates that the yarn fluctuates considerably in this case. The average value of $\mathrm{L}_{2}$ shows that the loop formation process clearly starts further inside the nozzle under wet texturing conditions. The average values of parameter $\mathrm{L}_{3}$ confirm that the filaments remain closer to the nozzle exit in wet texturing. This compares favourably with earlier investigations by Acar et al [5] using the original HemaJet nozzle with circular cross-section, which has similar dimensions and features to the rectangular nozzle used in the present tests, but has three air inlet holes.

The yarn motion analysis is interpreted in terms of four zones with distinct characteristics:

- $\quad$ Filament Yarn Feed Zone: Yarn path is between the wetting unit and the texturing nozzle. Filament yarn is enveloped by and virtually soaked in water and moves as one coherent bundle until it meets the secondary flow of air jet. Water surrounding the filament yarn and the spin finish are mostly blown off when they meet the fast counterflow of secondary flow jet. 
- Yarn-airflow Interaction Zone (inside the nozzle): The incoming air flow into the main channel splits up into supersonic and turbulent primary airflow and much weaker secondary airflow, as shown in Figure 4. The yarn enters the nozzle with secondary airflow in countercurrent. The filament separation point, where filaments start to open up, is located close to the air inlet orifice, and usually lies slightly on the secondary flow side. When the filament yarn continues to travel inside the nozzle, it comes under the influence of the primary airflow, both the yarn and the airflow travelling in the same direction. Constituent filaments begin to open-up and separate and generally exhibit random wavelike, undulating movements.

- Texturing Zone: The filament pattern displays a chaotic character. The separated filaments entangle and form into loops as they begin to leave the nozzle, as a result of the fluid forces exerted by the highly turbulent and supersonic airflow and the right angle turn enforced on to the textured yarn.

- Textured Yarn Zone: Loop and entanglement formation is complete; textured yarn is transported at right angle to the direction of airflow by the take-up rollers to a region which is outside the influence of the primary air jet.

\section{Re-Appraisal of Mechanism of Air-Jet Texturing}

In wet texturing, the friction characteristics change along the path followed by the yarn due to changes in the water content and quantity of spin finish on the yarn. The lubricating effect of the moisture induces a state of low friction whilst the yarn is inside the jet. Reduced friction in wet texturing between the filaments and also between filaments and other surfaces makes easier the relative motion of the filaments with respect to each other both in longitudinal and transverse directions. The state of yarn wetting, spin finish and friction is summarised in Table IX.

Table IX: State of yarn wetting, spin finish and friction in wet texturing

\begin{tabular}{|l|l|l|l|}
\hline & State of wetting & Spin finish level & State of friction \\
\hline $\begin{array}{l}\text { Filament yarn } \\
\text { feed zone }\end{array}$ & $\begin{array}{l}\text { Yarn is enveloped } \\
\text { by water acting as } \\
\text { lubricant }\end{array}$ & $\begin{array}{l}\text { Original spin } \\
\text { finish level }\end{array}$ & $\begin{array}{l}\text { Kinetic: low friction due to the } \\
\text { lubrication effect of water }\end{array}$ \\
\hline $\begin{array}{l}\text { Yarn-air flow } \\
\text { interaction zone } \\
\text { inside the nozzle }\end{array}$ & $\begin{array}{l}\text { Yarn is moist } \\
\text { inside the nozzle }\end{array}$ & $\begin{array}{l}\text { Reduced spin } \\
\text { finish }\end{array}$ & $\begin{array}{l}\text { Kinetic: low friction due to the } \\
\text { lubrication effect of water }\end{array}$ \\
\hline Texturing zone & $\begin{array}{l}\text { Water droplets in } \\
\text { the air flow is } \\
\text { blown off }\end{array}$ & $\begin{array}{l}\text { Further reduction } \\
\text { in spin finish }\end{array}$ & $\begin{array}{l}\text { Kinetic: low friction due to the } \\
\text { lubrication effect of mist in the } \\
\text { flow }\end{array}$ \\
\hline $\begin{array}{l}\text { Textured yarn } \\
\text { zone }\end{array}$ & $\begin{array}{l}\text { Yarn is virtually } \\
\text { dry }\end{array}$ & $\begin{array}{l}\text { Spin finish is at its } \\
\text { final reduced level }\end{array}$ & $\begin{array}{l}\text { Static: high friction due to the } \\
\text { reduced spin finish and } \\
\text { relatively dry yarn }\end{array}$ \\
\hline
\end{tabular}

The lower friction inside the jet gives way to higher friction, as the yarn leaves the texturing zone since the residual moisture is blown away by the primary jet leaving textured yarn virtually dry and containing only a small fraction of its original spin finish. Since there is no longer a relative 
motion between the constituent filaments of the yarn just textured, the higher static friction between the filaments prevails. This friction between the filaments of the wet textured yarn is higher than that of the dry textured yarn. This increase in friction in this region between the filaments of the wet textured yarn gives rise to improved cohesion and hence structural integrity of the yarn. Due to higher static friction the loops formed will be more firmly anchored into the core of the textured yarn and hence resist their removal under tension.

This explains why wet texturing, regardless of the yarn material, consistently results in yarns with greater structural integrity.

Dry texturing fails to perform in a similar way because the reduction in spin finish during the process is insignificant, so the kinetic frictional characteristics of the filament yarn remain much the same as its original form throughout the entire process. Furthermore, increase in interfilament static friction at the final stage of the process does not occur since the spin finish removal is negligible, resulting in a more loosely entangled, larger loops less firmly anchored to much the looser core, being more prone to be pulled out under tension.

\section{Conclusions}

This synthesis of available information from our research sheds new light on the mechanism of air-jet texturing and explains the dual role of water in air jet texturing in terms of two separate processes: loop formation and loop fixing/anchoring.

Water acts

- as a lubricant to generate a reduction in interfilament and filament/solid surface kinetic friction prior to and during the loop and entanglement formation stage.

- as an agent for the removal of spin finish from the surface of the filaments leading to an increase in static friction between the constituent filaments of the textured yarn.

We conclude that the effectiveness of wet texturing is explained by low inter-filament friction during the filament transport through the nozzle, followed by high friction in the textured yarn during the final loop fixing stage of the process. Whereas previous researchers have emphasised the loop creation phase, our work provides new insight insofar as it stresses also the part played by a final loop fixing or anchoring phase during yarn take-up.

\section{LITERATURE CITED}

1. AATCC (1997), Finishes in Textiles: Identification, American Association of Textile Chemists and Colorists, 94-1997

2. Acar M (1988), 'Factors Governing the Choice of Feeder Yarns Suitable for Air-jet Texturing', Chemiefasern/Textilindustrie, Vol. 38/90, No. 4 (April), 322- 326 (in German) and E35-E37 (in English) (1988)

3. Acar M and Demir A (1989), 'The Mechanism of Yarn Wetting', Chemiefasern / Textilindustrie, Man Made Fibre Year Book, pp 86-90, (1989).

4. Acar M, Turton RK, Wray GR, (1986a), 'An Analysis of the Air-Jet Yarn Texturing Process Part II: An Experimental Investigation of the Air Flow', Journal of the Textile Institute, 77, 1, 28-43, (1986). 
5. Acar M, Turton RK, Wray GR (1986b), 'An Analysis of the Air-Jet Yarn Texturing Process Part III: Filament Behaviour during Texturing', Journal of the Textile Institute, 77, 4, 235-246, (1986).

6. Acar M, Turton RK, Wray GR (1986c), 'An Analysis of the Air-Jet Yarn Texturing Process Part IV: Fluid Forces Acting on the Filaments and the Effects of Filament CrossSection Area and Shape', Journal of the Textile Institute, 77, No 4, 247-254, (1986).

7. Acar M, Turton RK, Wray GR (1986d), 'An Analysis of the Air-Jet Texturing Process, Part V: The Effect of Wetting the Yarns', Journal of Textile Institute, 77, 6, 359-370, (1986).

8. Acar M, Turton RK and Wray GR, (1987), 'Air Flow in Yarn Texturing Nozzles', Transactions of ASME, Journal of Engineering for Industry, 109, 3, 197-202, (1987).

9. Artunc H (1981), 'Air-jet Texturing of Drawn and of High-speed Polyester Yarns', Chemiefasern/Textilindustrie, 31/83, 4, 1981, pp289-297 and E29, (1981).

10. Bilgin S, Versteeg HK, Acar M (1996), 'Effect of Nozzle Geometry on Air-Jet Texturing Performance', Textile Research Journal, 66, 2, pp 83-90, (1996).

11. Bock G (1981), 'Texturing Filament Yarns in an Airflow - Tangling Mechanisms', ITB Spinning, 4/81, pp 359-389.

12. Bock G and Luenenschloss J (1982), 'An Analysis of the Mechanism of Air-jet Texturing', in: Textile Machinery: Investing for the Future, The Textile Institute, Manchester, 1982, p 359 (9pp).

13. Bock and Luenenschloss (1984), 'Der Verwirbelungsprozess beim Luftblastexturieren', Textil Praxis International, 39, pp 551-558, (1984).

14. Chand S (1995), The Role of Water in Air-jet Texturing (A Critical Review), Journal of the Textile Institute, Vol. 86, 3, 438-444, (1995).

15. Demir A (1987), The Air-jet yarn Texturing Process with Particular Reference to Nozzle Design and Improved Yarn Test Methods, PhD Thesis, Loughborough University, UK, (1987).

16. Demir A, Acar M, Turton RK, 'Air Flow in Nozzles' (1990), Textile Asia, 11, 8, 77-80 and 89-93, (1990).

17. Fischer K (1979) 'Aerodynamic Processes in Filament Yarn Production', Intern. Textile Bulletin/Spinning, 1979/1, 8pp, (1979).

18. Kothari VK, Sengupta AK and Rengaswamy RS (1991a), 'Role of Water in Air-Jet Texturing, Part I: Polyester Filament Feeder Yarns with Different Frictional Characteristics', Textile Res. J., 61, 9, pp 495-502, (1991).

19. Kothari VK, Sengupta AK, Rengaswamy RS (1991b), 'Role of water in air-jet texturing. Part II: Nylon 6 yarns', Textile Res. J., 61, 10, pp 575-580, (1991).

20. Lindberg J and Gralen N (1948), 'Measurement of Friction Between Single Fibres II: Frictional Properties of Wool Fibres Measured by the Fibre-Twist Method', Textile Res. J., 18, pp 287-301, (1948). 
21. Lawson-Hemphill (1997), Constant Tension Transport and Friction Test Instrument Manual, Lawson-Hemphill, Inc. Central Falls, RI, USA

22. Prevorsek D C and Sharma RK (1979), 'Fibre-fibre Coefficient of Friction: Effect of Modulus and Tan $\delta$ ', J. Applied Polymer Sci., 23, pp 173-184, (1979).

23. Sengupta AK, Kothari VK and Srinivasan J (1990), 'Mechanism of of-jet Texturing Process: Need for Reappraisal', Man-made Fiber Year Book, pp $74-77$ (1990).

24. Wray GR and Acar M (1990), 'Supersonic Jet Texturing of Yarns', 76th Thomas Hawksley Lecture, Proceedings of the IMechE, Part B: Journal of Engineering Manufacture, 204, 71-89, (1990). 